\title{
Economic and Legal Aspects of Digitalization as a Priority of the Strategic Development of the Capital Cities of the Ural Macro-Region
}

\author{
Ivan A. Antipin \\ Ural State University of Economics \\ Ekaterinburg, Russian Federation \\ aia87@mail.ru
}

\author{
Olga Yu. Ivanova \\ Ural State University of Economics \\ Ekaterinburg, Russian Federation \\ trtskmius17@mail.ru
}

\author{
Oleg A. Kozhevnikov \\ Ural State University of Economics \\ Ekaterinburg, Russian Federation \\ jktu1976@yandex.ru
}

\begin{abstract}
The article is devoted to the study of economic and legal aspects of digitalization as one of the priorities of the strategic development of the capital cities of the Ural macroregion. The relevance of the topic is due to the penetration into all spheres of life of the processes of formation of a postindustrial economy that are un-thinkable without digital technologies, currently unfolding in the Urals, generating new, previously unexplored trends in the transformation of urban economic systems. The methodological basis of the research is based on the theoretical positions of the innovation economy, strategic management, regional and spatial economics. The evaluation of the transformation processes of strategic guidelines for the development of cities, taking place due to the development of digital technologies, has been carried out using a combination of methods: logical, dialectical, cause-and-effect, content analysis, calculation of statistical indicators, etc. As a result of the study, barriers to managing digitalization processes were identified, prospects for the development of strategic planning in the area of setting priorities for scientific, technical and innovative development of cities were identified and recommendations for improving regulatory documents of the Russian Federation regulating forecasting and strategic planning were formulated. The article may be useful to university students, graduate students, research scientists, professionals involved in the development (actualization) of strategies for the socio-economic development of territories, state and municipal employees, as well as other interested parties.
\end{abstract}

Keywords-strategy; strategic planning; city, strategic priorities; digitalization.

\section{INTRODUCTION}

The strategic goal of Russia, approved in 2008, is "to achieve a level of economic and social development that corresponds to the status of Russia as the leading world power of the $21^{\text {st }}$ century, which occupies leading positions in global economic competition and reliably ensures national security and the realization of the constitutional rights of citizens" [1]. Achieving such a large-scale goal is impossible without systematic work on the development of the national economy, the introduction of information, telecommunication, network, and other competitive digital technologies. As noted by V.V. Putin, President of the Russian Federation, in his message to the Federal Assembly, "it is necessary to focus on areas where the powerful technological potential of the future is accumulating, a large-scale systemic program for developing the economy of a new technological generation, the so-called digital economy, should be launched" [2]. This statement preceded the development of the national program "Digital Economy of the Russian Federation" [3] and the launch of a series of priority federal projects, each of which contains aspects of digitization.

Such projects include:

- Improving the processes of organizing medical care based on the implementation of information technology" ("Ehealth");

- Implementation of an automated system for monitoring the movement of drugs from the manufacturer to the end consumer to protect the population from counterfeit drugs and promptly remove counterfeit and inferior drugs from circulation" ("Medicines. Quality and Safety");

- Modern digital educational environment in the Russian Federation" ("Modern digital educational environment");

\section{- Digital school.}

At the same time, as one of the tasks of the long-term socio-economic development of the Ural Federal District, "the 
The large cities of the macroregion, which are the drivers formation of a modern information and telecommunication infrastructure, ensuring a high level of accessibility and providing quality services on its basis" is declared [4]. The development of digitization in the Ural is supposed in line with the directions:

- the formation of a single information space;

- the transition to digital broadcasting in most of the District;

- the elimination of the "digital inequality" between the individual regions of the District;

- the introduction and widespread use of navigation and information systems based on the Global Navigation Satellite System (GLONASS) in the District;

- the creation of a universal logistics and information operator based on the national postal operator;

- the fourth-generation technology development, etc.

Enhancing the relevance of digitization processes and increasing attention to their development in strategic planning documents is being clarified under the prism of the fifth technological structure of sprouts of the post-industrial economy emerging as a result of the completion of the fourth and deployment in the economic space of the Ural. In the late $20^{\text {th }}$ and early $21^{\text {st }}$ centuries, the attention of researchers began to increasingly attract the trends of active modernization of traditional industries, taking place against the background of the formation of new sectors of the economy, called the "new industrialization" on the basis of innovative development and the changing role of technology. These trends are widely covered in various scientific publications, including Ural scientists [5-8].

The growth of high-tech science-intensive industries in the economic space of the Ural, including the creation of hightech electric trains, unmanned aerial vehicles, the invention of polymer materials with unique properties, new electronic and optical equipment, is not possible without the involvement of digital and information technologies, which are deeply integrated into all areas of the economy and public life, predetermining the emergence of a digital economy.

Given the fact that the Urals is a traditionally industrial region, the potential long-term socio-economic development of the Ural Federal District identified potential points of technological growth of the economy - metallurgy, machinebuilding, chemical-pharmaceutical and timber industries [4]. Given the fact that the Ural is a traditionally industrial region, the potential points of technological growth of the economy metallurgical, machine-building, chemical-pharmaceutical, and forestry complexes - have been highlighted in the potential long-term socio-economic development of the Ural Federal District [4]. They have signs of competitive industries that meet the criteria of technological prospects, including in new markets [9]. In particular, due to the Ural enterprises, the concept of "white metallurgy" has been introduced into use, which implies ultra-modern metallurgical production based on a combination of high, including digital, technologies. of industrial and scientific-technical development, are forced to impose even more stringent requirements on the formation of strategic documents for socioeconomic development and on the elaboration of strategic management mechanisms in these realities. Forming the future image of modern cities, developers and implementers of strategic documents, as a rule, have to work with large amounts of information. In this regard, the development strategies of the largest cities should include such terms as "digital economy", "digital and cognitive technologies", "big data", "databases", etc. Issues related to forecasting, strategic planning, and strategic management of digitization processes, as well as methodological support for their involvement in the development of the economy, are becoming increasingly important [10-13].

The basic legal framework for strategic planning at the national, regional, and municipal levels of government in the Russian Federation is Federal Law of June 28, 2014, No. 172 FZ On Strategic Planning in the Russian Federation [14]. coordination of the state and municipal strategic management and budget policy, strategic planning in the Russian Federation is carried out at the federal level, the level of the constituent entities of the Russian Federation, and the level of municipalities.

In the light of the above aspects, the purpose of this paper is to combine four aspects:

- the study of digitization as a direction of transformation of strategic priorities of the largest cities of the Ural macroregion,

- identifying barriers to managing digitization development processes,

- substantiating the prospects for the development of strategic planning in the field of prioritization of scientific, technical, and innovative development of cities,

- proposals for amending legislative and other regulatory legal acts of the Russian Federation governing the processes of strategic planning and forecasting the socio-economic development of the territories.

The analysis of strategies for the socio-economic development of the largest cities in this study was carried out according to the stages of the strategic planning and strategic management cycle: environmental analysis, goal setting, strategy construction (structure), and mechanisms for implementing the strategy, monitoring and management system for the implementation of the strategy.

\section{RESEARCH METHODOLOGY}

Systemic transformations in the strategic development of the country are impossible without the implementation of similar, coordinated processes in the regions and cities located in its territory. In June 2014, the Federal Law No. 172-FZ On Strategic Planning in the Russian Federation was approved in the Russian Federation. It does not contain a general definition of the term "strategy", although interpretations of more Art. 1 of the said Law establishes that within the framework of 
The concept of the digital economy is relatively new. The specific terms have been provided, including "the document of strategic planning", "the strategy of socio-economic development of the Russian Federation", "the strategy of spatial development of the Russian Federation", "the strategy of socio-economic development of the constituent entities of the Russian Federation", "the strategy of socio-economic development of the municipality". "The lack of legislatively approved wording is compensated by a wide range of definitions of the term "strategy" that appear in scientific sources [15-19].

Considering the best foreign and Russian practices, it should be noted that the strategic plan (strategy) should be a document of public agreement on the priority (strategically important) for various groups of the local community areas for development of the territory in which they live and work [20].

The need for a clearer understanding of the new requirements for documents of a strategic nature in order to increase their relevance to current realities is justified by a combination of interrelated circumstances:

firstly, the development of the modern world is based on progress, incl. in the scientific, scientific-and-technological, and innovative fields. This process is characterized by significant dynamics, the speed of the changes that are generated by the increasing globalization of economic, political, and socio-cultural life. Achievements and potential of this progress should correlate with the tasks stated in the strategic documents;

secondly, in a rapidly and continuously changing environment, the largest cities have to clearly determine the priorities of their strategic development and the ways to achieve them. Particular importance was attached to not just the development of development strategies, including strategies for the development of the digital economy, but the formation of the image of the future, for the achievement of which the corresponding strategies are being developed [9]. The importance of the problem of shaping the image of the future is emphasized in the National Technological Initiative, which highlights the need to plan work from the future, the socalled "preferred reality", to the present.

The experience of strategic planning of the largest cities in the world (Amsterdam, Barcelona, London, New York, Singapore, Stockholm, Rio de Janeiro, Chicago, etc.) indicates that more and more attention is paid to the role of information and communication technologies in the processes of improving the functionality of urban systems, the use of digital technologies, including telemedicine, distance learning, online commerce, 3D modeling, etc.

The most important global trend that accompanies the process of new industrialization is the emergence of industry 4.0 and the digital economy.

Industry 4.0 involves fundamental changes in the automation and digitization of technologies, and the transition from the Internet of people to the Internet of Things [23]. The Internet of Things provides the ability to remotely monitor and manage devices, to generate new ideas, to collect and to process information from big data streams in real time [24]. consequence of this is the widespread use of the terms "digital economy" and "digitization" without a clear distinction and uniform interpretation. Nevertheless, in the scientific literature, there are many approaches to the disclosure of the term "digital economy". The authors are close to the position of R. V. Meshcheryakov, Doctor of Economics, Professor, Member of the Russian Academy of Sciences, who believes that there are two approaches to the term "digital economy". The first approach is "classic": the digital economy is an economy based on digital technologies and, moreover, it is more correct to characterize exclusively the field of electronic goods and services (telemedicine, distance learning, sale of medical content, etc.). The second approach is an expanded one - the "digital economy" is economic production using digital technologies.

Thus, we consider digitization as one of the important directions of the strategic development transformation of the largest cities, and the technologies generated in its environment - as an actual tool for achieving strategic priorities in the urban economy and shaping the image of the future.

\section{RESULTS}

An analysis of the socio-economic development strategies of the largest cities of the Ural macroregion (hereinafter referred to as the strategies), carried out under the prism of the goal set in this study, allowed us to obtain the following results.

1. The strategic priorities of the largest cities of the Ural macroregion include the development of an innovationoriented economy, the creation of favorable conditions for the development and application of high (including digital) technologies.

So, for example, one of the seven strategic directions for the development of Yekaterinburg is "Yekaterinburg - an Interregional Innovation-Oriented Industrial and Financial Center". Among the objectives of the above strategic direction is "the development of the digital economy, aimed at improving the efficiency of interaction between business, government, and society, timely provision of information and communication services with modern infrastructure, institutional, technological, and human resources".

The Chelyabinsk Strategy is based on an innovative scenario. The main goal is the formation of the status of a modern metropolis, with the appropriate appearance, infrastructure development, level of services, quality of life. In the field of technology development, a three-level task is set: "to move from technology imports to technology development and to the independent creation of new technologies".

The strategic goal of the development of Perm is to improve the quality of life of the population on the basis of the innovative development of the city's economy. Its implementation is expected due to "...the development of a diversified economy based on dynamically developing and innovative sectors, the creation of conditions for the 
development of a knowledge economy and the transition of the urban economy to the sixth technological order".

The strategic goal of the development of Orenburg is to create conditions for improving the quality of life of the population through the development of the city's economy, combining the modernization of traditional industries and the emergence of new leaders in innovative economic development. According to the developers of the strategy, this is possible under the condition of "restructuring the economy, the formation and development of the 'new economy', new economic specialization, the emergence of new leaders in economic development...".

The formulation of the general goal of Kurgan does not state the development of an innovative economy, however, the objectives for the subgoal "Development of Economic Potential" include "creating conditions for increasing the innovative development of the economy of Kurgan and forming on its basis an innovative and technological center of Kurgan Region".

The priority of Ufa is to become a high-tech center. A "strong economy", as indicated in the strategy of this city, is achieved on the basis of "promoting the sustainable development of industry and innovation".

The triune goal of Izhevsk also includes the "transition to an innovative economy", which requires work in key areas (tasks) - "entrepreneurial (manufacturing), investment activity, small and medium-sized enterprises", "labor market regulation", "development of the economic basis of the city".

Thus, at the level of municipal legal acts of municipalities - the capitals of the constituent entities of the Russian Federation in the Ural macroregion, modern trends of innovative development of the economy of the municipal level of government are fixed and taken into account.

2. Despite the identified strategic priorities based on the content analysis (its brief results are given in Table 1), we can conclude that most of the strategies of the cities studied practically do not contain concepts related to the concept of the digital economy and describe the mechanisms of its formation and development.

TABLE I. FREQUENCY OF TERMS USED IN DEVELOPMENT STRATEGIES OF THE LARGEST CITIES OF THE URAL MACROREGION

\begin{tabular}{|c|c|c|c|c|c|c|c|}
\hline Terms & 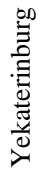 & 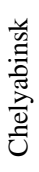 & $\underset{0}{0}$ & $\begin{array}{l}\text { bo } \\
\vdots \\
0 \\
0 \\
0 \\
0\end{array}$ & 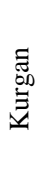 & $\stackrel{\pi}{\square}$ & $\begin{array}{l}\frac{y}{0} \\
\frac{d}{N} \\
\frac{1}{N}\end{array}$ \\
\hline $\begin{array}{l}\text { Information (processes, } \\
\text { technologies, systems, etc.) }\end{array}$ & 36 & 18 & 30 & 1 & 4 & 2 & 1 \\
\hline $\begin{array}{l}\text { Digital (economics, } \\
\text { technology) }\end{array}$ & 6 & 1 & - & - & - & 8 & - \\
\hline Big data & - & - & - & - & - & - & - \\
\hline Smart city & 2 & - & - & - & - & 2 & - \\
\hline Internet of Things & 1 & - & - & - & - & 1 & - \\
\hline Industry 4.0 & - & - & - & - & - & - & - \\
\hline New industrialization & - & - & - & - & - & - & - \\
\hline
\end{tabular}

This circumstance can partially be explained by the fact that strategic planning documents are legal acts, the development of the text of which differs from the generally accepted in the economic literature. Not all generally accepted words and phrases used in the economic literature can be "automatically" transferred to the text of legal acts. In particular, according to the rules of legal technology, when forming the text of a legal act, one should always pay attention to the fact that the terms used in the text of a legal act have generally recognized meaning, whether the terms and concepts used in the text of a legal act ensure unity with the concepts and terminology used in acts superior in legal force.

3. Specially designed programs (projects) for the development of the digital economy in general and individual digital technologies in particular are reflected only in the strategies of two of the seven cities studied.

In particular, the strategic program "Digital Yekaterinburg" is highlighted in the development strategy of Yekaterinburg.

In the development strategy of Ufa, as a part of the implementation of the priority direction "Creating an enabling environment for the development of small and medium-sized enterprises in priority areas of the city's economy", the project "Digital Platform for Supporting the Production and Marketing Activities of SMBEs (small and medium-sized business entities) - the growth of the contribution of small and medium-sized businesses to the city's economy" has been provided; and in the framework of the priority area "Effective and Open Authority", the "Digital Administration" project. The proposed structure of the "Digital Yekaterinburg" strategic program can be taken as a basis for forming the priorities of scientific-and-technical and innovative development of any other city.

4. In the development strategies of the studied cities of the Ural macroregion, there is no block for strategic management of digitization development processes and an analysis of the directions of using their potential in the urban economy.

The development of this analysis faces a number of barriers that can be divided into two groups: information and methodological ones.

Information barriers include the following aspects:

A) There is no comprehensive approach to monitoring digital transformation, including the measurement of the main directions and factors for the effective use of information and communication technologies (hereinafter referred to as "ICT"). It should be emphasized that in the statistical collections "Regions of Russia. The main Socioeconomic Indicators of Cities" information on the development of ICT and digital technologies in the largest cities of the country has not been provided. In the statistical collections "Information Society in the Russian Federation", there is no urban section (only regional one). The latest statistical compilation "Information Society: Development Trends in the Constituent 
Entities of the Russian Federation" was published in 2015 and it also lacks an urban section of the analysis;

B) Current forms of federal statistical monitoring do not reflect modern processes of digital transformation; there is no correlation with international standards. This problem does not allow taking into account the specifics of the digital transformation of state and municipal government, healthcare, culture, education, science, etc., and making correct international comparisons [30].

In this regard, we believe that there is a need for making appropriate amendments to the Decree of the Government of the Russian Federation of November 11, 2015, No. 1218 On the Procedure for the Development, Adjustment, Monitoring, and Control of the Implementation of the Forecast of Socioeconomic Development of the Russian Federation for the Long Term regarding development and accounting indicators of development and implementation of digital technologies in the field of state and municipal government in the implementation of the socio-economic development in the whole of the Russian Federation and its territorial units.

We offer a list of indicators of the socio-economic development, with the help of which indicators of the socioeconomic development it is possible to evaluate the development of digitization processes:

The share of households with broadband Internet access, in the total number of households (at the end of the period), percentage;

The volume of external traffic (incoming and outgoing data outside the municipality) using modern information and telecommunication systems (excluding traffic within corporate networks), terabyte;

The share of municipal services provided by local authorities in electronic form using the Unified portal of state and municipal services and the official website of local authorities on the Internet, of the total number of services provided by local authorities, percentage;

The share of applications for municipal (state) services received in electronic form, of the total number of applications, percentage;

The share of specialists in the field of information technology and communications (graduates of universities and specialists undergoing advanced training and retraining on the basis of universities), of the total number of specialists trained by universities, percentage.

Among the methodological barriers, one can single out the lack of methodological tools for assessing the readiness of the urban environment for digitization and the adaptability of digital technologies in the urban economic space, and for assessing the socioeconomic effects of using digital technologies. The areas of development of the methodology for assessing the digital transformation should be such areas as ICT infrastructure, human capital, the business environment, government policy and regulation, information security and trust.
Due to the fact that in accordance with Part 3 of Article 10 of the Federal Law dated June 28, 2014, No. 172-FZ On Strategic Planning in the Russian Federation, the Government of the Russian Federation is charged with the methodological support of strategic planning, it seems necessary to develop and approve new methodological tools at the level of this federal executive body authorities, allowing to give an adequate assessment of the readiness of the urban environment for digitization and adaptability of digital technologies in the urban economic space, an assessment of the socioeconomic effects of the use of digital technologies.

\section{DISCUSSIONS}

Digitization affects all key sectors and spheres of modern life, which are concentrated in cities, while being integral parts of their livelihoods. However, various cities of our country are at different stages of the spread and adaptation of digital technologies. In general, two levels of digitization can be distinguished: the primary one implies the availability, quality, and availability of digital infrastructure; the secondary one the intensity and skills of using the existing infrastructure, the nature of the services used - the existence of "digital competencies".

Most Russian cities are at the first level of digitization, their residents make purchases online, receive electronic government services, communicate on social networks, etc. And only a few of the largest cities in Russia are moving to the second level of digitization. The second level involves the large-scale introduction of artificial intelligence technologies, cybersecurity technologies, the Internet of Things (industrial Internet), large databases, and solutions developed for smart cities. So, the Research Institute of Technology and Communications (Moscow), conducting a study in 2017, compiled the Top 10 most smart cities in Russia based on an assessment of a set of reasonable indicators. It included (as the integral value decreases) Moscow, St. Petersburg, Kazan, Yekaterinburg, Krasnoyarsk, Novosibirsk, Ufa, Sochi, Perm, and Rostov-on-Don. Obviously, this list includes only three cities of the Ural macroregion, in the strategies of which digitization is named among the priorities of strategic development.

There are studies demonstrating that the development strategies of an increasing number of foreign cities (Amsterdam, Barcelona, London, New York, Singapore, Stockholm, Rio de Janeiro, Chicago, and others) emphasize the role of information and communication technologies in the process of improving functionality urban systems [30].

Among all the materials considered in the study, the socioeconomic development strategy of Yekaterinburg has the most clearly coherent structure of strategic directions, each of which presents in detail the target vector, main tasks, strategic vision, as well as indicators for monitoring and evaluating effectiveness, without which achievement development priorities of the city is impossible. The strategy of the city presents a mature program for the development of digitization and the use of its potential in the urban economy - "Digital Yekaterinburg". As a part of this strategic program, a systematic transition to the development of intellectual urban 
infrastructure has been worked out, and information security is provided for in the context of digitization growth. The mechanisms for implementing the strategic program are the "Modern Information Environment" and "IT Cluster" projects. A system of indicators of the strategic direction effectiveness has been developed, and their values have been predicted.

In our opinion, just such an approach to strategic planning, tested in Yekaterinburg, should be taken as a basis in the formation of priorities for the scientific-and-technical and innovative development of other cities in the macroregion.

\section{CONCLUSIONS}

This paper discusses long-term systemic challenges, as well as the development priorities of the Russian Federation, to achieve which a clear understanding of the development of strategic areas of development and mechanisms for their implementation is required. Attention is focused on the need to apply mechanisms of strategic planning and strategic management.

Strategic planning and strategic management have become tools for organizing the work of authorities with other groups of stakeholders, a guarantee of the possibility of successfully achieving their goals. It depends on how correctly the priorities of strategic development are defined, whether they are correctly implemented, whether the system of strategic control is built, etc., the results of socio-economic development of the territories of different hierarchical levels depend.

The study allowed the authors to reasonably formulate the following conclusions:

1. One of the most important priorities of the strategic development of the largest cities and the entire Russian Federation are scientific, technological, and innovative development aimed at achieving progress in socioeconomic development, creating comfortable living conditions for the population, as well as opportunities for self-realization.

2. One of the modern tools necessary to achieve strategic development priorities and transform them in the largest cities and the entire Russian Federation is the digital economy, digitization.

3. Urban development management should be clearly planned, rational, and predictable. Accordingly, it is necessary to apply strategic planning and strategic management. A prerequisite for the success of the strategy is to build strategic directions (priorities), as well as mechanisms for their implementation. Proper strategic planning and strategic management ensure high rates of socio-economic development of the city, strengthening its competitiveness.

4. Modern strategies for the development of cities of the Russian Federation do not fully reflect current global trends and should be updated in order to better meet modern realities and global challenges.

5. When planning the scientific, technological and innovative development of a large city (regional capital), the experience of Yekaterinburg can be used as an example, a standard. The Strategic Plan for the Development of Yekaterinburg proposes a structure of strategic directions, each of which presents in detail the target vector, main tasks, strategic vision, as well as programs, projects, and performance indicators, without which the achievement of city development priorities is impossible. This is a kind of "recipe" that can be applied in other cities.

6. Legislative and other normative legal acts of the Russian Federation regulating the processes of strategic planning and forecasting the socioeconomic development of territories require an adjustment. In particular, the Decree of the Government of the Russian Federation of November 11, 2015, No. 1218 On the Procedure for the Development, Adjustment, Monitoring, and Control of the Implementation of the Forecast of Socioeconomic Development of the Russian Federation for the Long Term regarding the development and accounting of development indicators and the introduction of digital technologies in the field of state and municipal government in the implementation of socio-economic development of both the whole of the Russian Federation and its territorial units. It also seems necessary to develop and approve new methodological tools at the level of this federal executive body that allows an adequate assessment of the readiness of the urban environment for digitization and adaptability of digital technologies in the urban economic space, an assessment of the socioeconomic effects of the use of digital technologies.

\section{References}

[1] On approval of the Concept of long-term socio-economic development of the Russian Federation for the period up to 2020: Order of the Government of the Russian Federation of 17.11.2008. No. 1662-r [Electronic resource]. - Access mode: - Help legal system "Consultant Plus".

[2] Message from the President of the Russian Federation to the Federal Assembly of the Russian Federation dated 12/01/2016 [Electronic resource]. - Access mode: - Help legal system "Consultant Plus".

[3] On the approval of the program "Digital Economy of the Russian Federation": Order of the Government of the Russian Federation of July 28, 2017 No. 1632-r [Electronic resource]. - Access mode: - Help legal system "Consultant Plus".

[4] Strategy for socio-economic development of the Ural Federal District for the period until 2020: Order of the Government of the Russian Federation of October 6, 2011 No. 1757-r [Electronic resource]. Access mode: http://zakonbase.ru.

[5] Animitsa EG, Silin YP Middle Urals on the way to new industrialization // Regional Economy. - 2013. - No. 3. - P. 71-80.

[6] Ivanov V.V. Problems of scientific and technological development of Russia in the context of the industrial revolution // Innovations. 2016. No6 (212). P. 3-8.

[7] Silin, Ya. P. Regional Aspects of the New Industrialization / Ya. P. Silin, E. G. Animitsa, N. V. Novikova // Regional Economy. - 2017. - T. 13, No. 3. - P. 684-696.

[8] Tatarkin A.I., Romanova O.A. Theoretical foundations and stages of the new industrialization of the Russian economy // GRAND ALTAI RESEARCH \& EDUCATION. - 2014 .-- P. 60-70.

[9] Romanova O.A. Strategies for the socio-economic development of the regions of the Russian Federation in the context of the challenges of the digital economy // Izvestia Ural State Economic University. - 2018. - T. 19, No. 3. - P. 55-68.

[10] Animitsa, E. G., Peshina, E. V., Bochko, V. S., Animitsa, P. E. Conceptual approaches to developing a development strategy for a single-industry city // Ural. state econ. University, Institute of 
[21] Albino, V., Berardi, U., \& Dangelico, R. M. (2015). Smart cities: Definitions, dimensions, performance, and initiatives. Journal of Urban Technology, 22(1), 3-21.

Yekaterinburg: Publishing house of Ural State Economic University, 2010. - $81 \mathrm{p}$.

[11] Silin, Y.P. A study of the priorities of the strategic development of a new industrial city // Ya. P. Silin, E. B. Dvoryadkina, I. A. Antipin // The Manager. - 2018. - T. 9, No. 6. - S. 2-16

[12] Surnina N.M., Shishkina E.A. Development of the methodology of regional strategic planning: improving coherence and effectiveness // The Manager. 2013. No. 1 (41). P. 56-63.

[13] Antipin I.A. Digitalization as a tool for transforming the strategic development of the territory // Theory and practice of social development. 2018. No. 12. P. 90 - 94.

[14] On strategic planning in the Russian Federation: Federal Law of June 28, 2014 No. 172-FZ [Electronic resource]. - Access mode: http://www.kremlin.ru/acts/bank/38630

[15] The development strategy of the largest city: a look into the future (scientific and methodological approach): monograph / Scientific. hand.aut. call prof. E.G. Animica and prof. V.S. A barrel. Yekaterinburg: Ural State Economic University-IE Ural Branch of the Russian Academy of Sciences, 2003.600 p.

[16] Fathutdinov R.A. Strategic management. M .: Delo, 2005.448 p.

[17] Utkin E.A., Denisov, A.F. State and regional government. M .: IKF "ECMOS", 2002.320 p.

[18] Turgel I.D. Monospecialized city: theory and practice of strategic management of socio - economic development. Yekaterinburg: Publishing House Ural. state mining geol. Academy, 2001.259 p.

[19] Surnina N. M. Methods of strategic analysis and planning at the national, regional and corporate levels (study of specific situations). Yekaterinburg: Ural State Economic University, 2004.200 p.

[20] Management of municipal economic development / ed. G.Yu. Vetrova. M.: "Fund Institute for Urban Economics", 2009. 258 p.
[22] Angelidou, M. The role of smart city characteristics in the plans of fifteen cities. Journal of Urban Technology, 2017, 24(4), P. 3-28.

[23] Babar, M., \& Arif, F. (2017). Smart urban planning using Big Data analytics to contend with the interoperability in Internet of Things. Future Generation Computer Systems, 77, 65-76.

[24] Lavrikova, Y. G., Antipin, I. A., Pryadein, \& Suvorova, A.V S. A. (2017). Major City Development Forecast\&58; Designing the Innovative Future. Economic and Social Changes: Facts, 6(48), 214-235.

[25] Lom, M., Pribyl, O., \& Svitek, M. (2016, May). Industry 4.0 as a part of smart cities. In Smart Cities Symposium Prague (SCSP), 2016 (pp. 1-6). IEEE.

[26] Morrar, R., Arman, H., \& Mousa, S. (2017). The Fourth Industrial Revolution (Industry 4.0): A Social Innovation Perspective. Technology Innovation Management Review, 7(11), 12-20.

[27] Ojasalo, J., \& Kauppinen, H. (2016). Collaborative innovation with external actors: an empirical study on open innovation platforms in smart cities. Technology Innovation Management Review, 6(12).

[28] Introduction to the Digital Economy / A.V. Keshelava, V.G. Budanov, V.Yu. Rumyantsev and others; under the general. ed. A.V. Keshelava / M .: VNIIGeosystem, 2017.28 p.

[29] Atzori, L., Iera, A., \& Morabito, G. The internet of things: A survey. Computer networks, 2010, 54 (15), R. 2787-2805.

[30] Shaposhnik S.B. Measurement of the digital economy: international standards and Russian statistics / Lomonosov readings, Moscow State University Lomonosov [Electronic resource]. - URL: -https: //digital.msu.ru/wp-content/uploads/2018-04-19-Shaposhnik.pdf (date of publication: 04/19/2018). 